\title{
I Premio de Teatro George Woodyard
}

\section{Laurietz Seda}

El Premio de Teatro George Woodyard ha sido creado por quien escribe estas líneas con el apoyo del Departamento de Lenguas Clásicas y Modernas y su sección de Español de la Universidad de Connecticut en honor al Dr. George Woodyard, uno de los pioneros de la investigación sobre el teatro latinoamericano en la academia estadounidense. Los objetivos primordiales son estimular, apoyar, hacer accesibles y promover la creación de obras teatrales de alta calidad. El premio consiste de 2,500 dólares más gastos de viaje (ida y vuelta) a la Universidad de Connecticut, gastos de estadía por dos noches y publicación de la obra en Latin American Theatre Review. Para mayor información sobre las bases, fechas y fallos del premio se debe visitar la siguiente página electrónica: $<\mathrm{http}$ ://www.languages. uconn.edu/programs/awards.html>.

En esta primera edición se recibieron 106 obras provenientes de México, Argentina, Chile, Uruguay, Venezuela, Colombia, Cuba, Costa Rica y Estados Unidos. Luego de una deliberación sobre 11 obras seleccionadas, un destacado jurado de investigadores de la academia estadounidense integrado por Jacqueline E. Bixler (Virginia Tech University), Gastón Alzate (California State-Los Angeles) y Stuart Day (University of Kansas) decidió otorgar el I Premio de Teatro George Woodyard a la obra La culpa la tuvo el tranvía presentada bajo el seudónimo "Esmeralda." Una vez abierto el sobre sellado la autora resultó ser la argentina Cristina Merelli. El jurado destacó la complejidad, el agudo sentido del humor y la fuerza de las constantes tensiones dramáticas que se van revelando para crear una obra eficazmente elaborada que atrapa al lector desde sus primeros diálogos.

Cristina Merelli es directora, actriz, dramaturga, guionista de cine, cuentista y poeta. Ha participado en festivales de Argentina, Venezuela, Puerto Rico, España y Estados Unidos, y en años consecutivos sus obras han sido 
seleccionadas para participar en el ciclo argentino de Teatroxlaidentidad. Tiene en su haber unas 35 obras teatrales entre las que se encuentran $\mathrm{La}$ gota que horada la piedra (I Premio de Teatro Nacional de Humor), Nidito de amor (Premio Proteatro), Teléfono (Premio Teatroxlaidentidad 2001), Humo de leña verde (Premio Teatroxlaidentidad 2002) y Al sur del paraíso (III Premio del Primer Concurso Iberoamericano de Textos Teatrales hacia una Nueva Dramaturgia otorgado por el CELCIT de Argentina).

La culpa la tuvo el tranvía es una obra elaborada en contrapunteo entre la relación de una pareja (un escritor fracasado y una mujer inculta) que aborda su matrimonio con juegos cargados de humor negro y la narración de una historia aparentemente escrita por Juan Manuel, el marido. El final de la obra nos devela que Juan Manuel no ha sido el auténtico autor de la narración, sino que ésta proviene de su padre quien solía contarle cada año para su cumpleaños un pedazo de dicho cuento, irónicamente dejándolo inconcluso cuando muere atropellado por un tranvía, y embarcando a Juan Manuel en una búsqueda de 40 años por encontrar el final. Beta, la esposa, desde que comienza a escuchar la narración sólo se interesa por conocer el final, por tanto intenta provocar a su marido mintiéndole al confesarle que ha sido la amante del hermano de éste. Dicha confesión conlleva a que Juan Manuel se suicide y que Beta, al igual que los lectores (y espectadores) se queden sin conocer el final de la narración del esposo.

Los enigmas de la obra de Merelli funcionan como juegos entre una pareja que busca un aliciente para escapar del aburrimiento de la rutina matrimonial. Para los lectores y espectadores los enigmas trabajan como elementos metatextuales que le obligan a mantener el interés por la lectura y a descubrir que no existe un desenlace perfecto, sino que con cada final aparece un nuevo comienzo. Ambos finales, el de la historia narrada por Juan Manuel y el del texto de Merelli respiran el aire de la inconclusión al verse fracasados por la muerte del creador o del protagonista. El desenlace de La culpa la tuvo el tranvía irónicamente es uno muy bien elaborado con una fuerte dosis de cinismo, humor negro, absurdo y sorpresa que da comienzo a un nuevo enigma provocado por el gesto de indiferencia de Beta: iha muerto Juan Manuel realmente o es parte del juego a que recurre este matrimonio para salir del aburrimiento de su rutina cotidiana? La combinación de todos estos elementos hacen de La culpa la tuvo el tranvía una obra bien estructurada que combina y contrapone con humor los temas de la creación y la ficción literaria con las relaciones de pareja. 